\title{
O discurso psicológico de John Dewey*
}

\author{
ERIKA NATACHA FERNANDES DE \\ ANDRADE \\ Universidade Estadual Paulista
}

MARCUS VINICIUS DA CUNHA

Universidade de São Paulo

\begin{abstract}
Em trabalhos como "Psychology as philosophic method" (Dewey, 1886), "The reflex arc concept in Psychology"(Dewey, 1896/1998) e "The need for social psychology" (Dewey, 1917), o filósofo americano John Dewey (1859-1952) conceitua "natureza humana" como conjunto coordenado de sensações e ideações, contrariando a tese que define a referida natureza como simples arranjo de entidades independentes. $\mathrm{O}$ autor também afirma que se deve entender a conduta humana como comportamentos que se desenvolvem na relação da "natureza humana" com o ambiente natural e social.

Conhecer o significado de "natureza humana" é essencial para situar os principais temas da filosofia deweyana: democracia e educação - como se nota no livro que leva esse título, uma das obras capitais da pedagogia contemporânea (Dewey, 1916/1958). Para obter uma medida de valor da vida social em benefício do modo de vida democrático, como é a proposta de Dewey, é preciso examinar não só os dados da realidade, mas também os mecanismos que influem na constituição do homem. No campo educacional, compreender a formação da personalidade é imprescindível para deliberar sobre os fins da educação.
\end{abstract}

* As pesquisas que originaram este trabalho foram subsidiadas pela Fundação de Amparo à Pesquisa do Estado de São Paulo (FAPESP) e pelo Conselho Nacional de Desenvolvimento Científico e Tecnológico (CNPq). 
As reflexões de Dewey referentes ao tema "juízo valorativo", vinculadas a uma teoria moral e ética, abordam enfaticamente a premência de estudos que elucidem o que é a "natureza humana". Nessa área, o autor recorre a análises psicológicas, visando encontrar parâmetros que permitam ao indivíduo pensar reflexivamente, fora da imediaticidade da experiência (Dewey, 1939/2009). Ao destacar a necessidade de tratamento científico da "natureza humana" como algo coletivo, Dewey reconhece a centralidade da psicologia para o desenvolvimento de uma nova ciência social, um conjunto de saberes que se ocupe da experiência humana em comunidade.

O objetivo deste trabalho é esclarecer o significado de "natureza humana" na filosofia de Dewey, bem como as relações desse conceito com a proposta de uma nova ciência social, a qual, segundo o autor, virá auxiliar na formação psíquica e comportamental das pessoas. Para atingir esse objetivo, tomaremos como objeto de estudo uma obra fundamental no conjunto da produção do filósofo, no que diz respeito aos temas em pauta. Trata-se do livro Human nature and conduct: an introduction to social psychology, no qual Dewey (1922/2002) discute questões pertinentes à psicologia, no âmbito de seu pensamento filosófico. ${ }^{1}$

O presente texto seguirá a ordem em que os argumentos se apresentam no livro, cujo ponto de partida é a discussão do psiquismo, no intuito de redefinir o que é o humano, e cuja conclusão consiste na proposição das bases de uma nova ciência psicológica. A metodologia empregada na análise do discurso do autor segue os estudos desenvolvidos pelo Grupo de Pesquisa Retórica e Argumentação na Pedagogia (USP/CNPq), cujos fundamentos encontram-se na obra Tratado da argumentação de Perelman e Olbrechts-Tyteca (2002), pertencente a uma nova abordagem da filosofia de Aristóteles (Berti, 1997).

A "nova retórica" concebe a relação estabelecida entre o autor de um texto e seus leitores como um intercâmbio entre um orador e seu auditório, permitindo compreender de que maneira o discurso é articulado para obter a adesão de determinada audiência. Considera-se que a efetividade de um discurso pode ser estudada por intermédio das estratégias argumentativas empregadas pelo autor, dentre as quais se destacam os exemplos, por meio dos quais se busca fundamentar uma regra a partir de casos particulares; as ilustrações, usadas para reforçar a adesão a uma regra já aceita; o modelo, em que um comportamento particular serve para fundamentar uma regra geral; a analogia, cuja especificidade reside no estabelecimento de similitudes entre objetos pertencentes a diferentes áreas; e os pares filosóficos, resultantes de dissociações de noções.

Outra fonte metodológica aqui adotada é o trabalho de Toulmin (2001), Os usos do argumento, situado no campo da lógica modal e igualmente pertencente ao movimento de revisão da filosofia aristotélica. Recuperando as lições de Aristóteles, os layouts argumentativos sugeridos por Toulmin (idem, p. 137) mostram que a análise lógica de um discurso deve elucidar a natureza das premissas que sustentam as alegações que se apresentam como conclusões dos raciocínios.

1 Nas próximas menções a esse livro, indicaremos somente o ano da edição consultada (2002), lembrando que todos os trechos citados foram traduzidos pelos autores deste artigo. 
Seguindo essas teorizações, buscaremos examinar as estratégias argumentativas do livro Human nature and conduct, bem como elucidar a constituição dos principais raciocínios nele contidos, explicitando as premissas que fundamentam suas conclusões. Mediante tais análises, este trabalho espera fornecer elementos para um debate que conjugue os campos da psicologia, da filosofia e da educação, tendo em vista as contribuições e também as limitações da teoria deweyana.

\section{HÁBITO, INSTINTO E INTELIGÊNCIA}

Entendendo que a vida mental existe "dentro e por causa de nosso ambiente", Dewey (2002, p. 327) conceitua uma consciência geral ou coletiva, proveniente da experiência associativa entre os seres humanos, e uma consciência do sujeito, surgida em meio a essa mente generalizada, sendo que o eu individual torna-se particularizado ao entrar em contato com os hábitos coletivos. Para Dewey (idem, p. 38), os elementos nomeados como "eu", "personalidade" e "caráter" representam "a interpenetração dos hábitos", o que, por sua vez, resulta de conflitos entre os variados hábitos e instintos e sua subsequente coordenação, a qual se realiza por meio da deliberação inteligente.

Ao discorrer sobre a formação psíquica e seus elementos constituintes, o fio condutor da argumentação desenvolvida por Dewey é o termo "conduta", cujo significado é "experiência prática". Tornar claro esse ponto de partida, o lugar de onde partem as manifestações do orador, constitui uma estratégia retórica fundamental para buscar consenso com o auditório, para que seja possível desenvolver outros raciocínios a partir dali. O lugar assumido pelo discurso deweyano pode ser designado, portanto, lugar da prática.

Do ponto de vista da prática, os hábitos são adquiridos em meio à conduta, afirma o filósofo. Exemplificando, Dewey (idem, p. 16) diz que atributos como "honestidade, castidade, maldade, irritação, coragem, vulgaridade, diligência, irresponsabilidade, não são posses privadas de uma pessoa", mas hábitos que ela adquire. Uma ilustração serve para Dewey (idem,p. 58) mostrar o poder de influência dos costumes: ao nascer, o bebê possui predisposição para aprender a falar qualquer língua, mas aprende a linguagem daqueles que o cercam porque essa é uma condição imprescindível para compreender os desejos dos outros, bem como os meios para satisfazê-los.

Para esclarecer o sentido dessa aquisição social e cultural, o filósofo rejeita as ideias elementistas e associacionistas presentes no campo da psicologia e da filosofia, as quais afirmam o valor da repetição de ações específicas. Para Dewey (idem, p. 15), "hábito é arte". Essa expressão inovadora significa que hábito não é apenas "reflexão", tampouco simples "repetição". Colocar um desses termos como norma para distinguir o valor do outro é uma falácia, diz o autor, pois exprime uma polarização que em nada contribui para elucidar a prática.

Na prática, em atividades sociais concretas, sempre que se busca alterar o estado atual das coisas mediante ações que conjugam planejamento e domínio de meios e fins, estão envolvidos aspectos emocionais e intelectuais. Os hábitos possuem uma 
característica ativa, inteligente, processual e contínua que vai além de simples treino. Mas o treino e a mecanização também participam, de maneira imprescindível, pois, se cada pequena ação tiver que ser conscientemente buscada e intencionalmente desempenhada, sua execução será dolorosa, e o produto, bastante desajeitado. Como ocorre na execução de um instrumento musical, Dewey (idem, p. 71) considera que a "técnica ou o seu mecanismo se funde com o pensamento e o sentimento".

Sobre os instintos, também denominados "impulsos", Dewey (idem, p. 89) afirma que, por si sós, como meras ações orgânicas, eles nada significam. Por esse motivo, o autor não analisa o aparato de disposições inatas, supostamente componentes de uma "dotação natural do homem ao nascer". Considerando exclusivamente a conduta, o que importa é a ação prática e social, são os significados, que não são inatos. Segundo Dewey (idem, p. 92), o que recebemos primeiramente são os hábitos. Os instintos são moldados e ganham significado quando imersos no âmbito dos costumes sociais, sendo preciso entendê-los como um capital nativo que é "modificado pela interação com diferentes ambientes”, adquirindo sentido nas relações práticas da vida.

Dewey (idem, p. 165) define os impulsos como "força, urgência", uma "indispensável fonte de liberação” (idem, p. 105). Entretanto, tais forças só adquirem essa característica quando empregadas para "o revigoramento e a renovação" dos hábitos (idem, p. 169), uma vez que o seu significado advém do social, esfera em que podem servir tanto para a reprodução quanto para a renovação. Como força renovadora, os instintos têm significados incompletos, mostrando-se flexíveis; seu resultado depende de como são entrelaçados reciprocamente, o que, por sua vez, varia conforme as "oportunidades de expressão" e as "inibições proporcionadas pelo ambiente social". Por serem incompletos e flexíveis, os impulsos assumem o aspecto de originalidade, possibilitando a reconstrução cultural.

Por esse motivo, o filósofo afirma que o capital instintivo é passível de ser educado. Dewey (idem, p. 96) discorre sobre a possibilidade de um "tratamento deliberado dos impulsos", uma educação que não seja mera obediência aos costumes presentes nas associações adultas, nem a total liberação para quaisquer caminhos. A ausência de tratamento educativo pode fazer com que as atividades impulsivas sejam liberadas de maneira explosiva, ou, alternativamente, que sejam reprimidas, confinadas à introspecção, sendo essas duas vias igualmente prejudiciais à constituição mental.

$\mathrm{O}$ autor se opõe às teorias que concebem os instintos como unidades fixas e inatas, classificados em categorias e apresentados quantitativamente; afirmar a existência de impulsos isolados correspondentes a determinadas forças e condutas, como fazem certos autores, é simplificar a complexidade da vida. Para Dewey (idem, p. 153-154), a teoria psicanalítica falha ao atribuir "o fenômeno do distúrbio e do conflito que acompanha as relações sexuais a manifestações de uma força singular original, ou seja, a Libido", e ao tratar fenômenos "que são sintomas peculiares da civilização ocidental atual como se fossem efeitos necessários de impulsos inatos e fixos"; falha também ao afirmar que "os hábitos mentais podem ser corrigidos unicamente por meio de algum tipo de manipulação psíquica”, sem referência às distorções do meio habitual já formado (idem, p. 34). 
Para Dewey, a inteligência é o que responde pela equilibração entre hábitos e impulsos, conduzindo a um termo consensual para resolver problemas da experiência. A atividade inteligente abarca o pensamento reflexivo e a conduta moral, pois, para Dewey (idem, p. 190), seu sustentáculo é a deliberação, que é "um ensaio dramático (na imaginação) de possíveis linhas de ação que são variadas e mutuamente competitivas". Esse processo começa quando se dá o "bloqueio da ação eficiente manifesta", devido ao "conflito entre hábitos estabelecidos e novos impulsos liberados". O desequilíbrio impede que a ação se desenvolva normalmente e, então, "cada hábito, cada impulso envolvido na suspensão temporária da ação manifesta é revezado e testado", justamente para alcançar uma síntese, uma previsão qualitativa das possíveis consequências, para que se possa decidir sobre uma linha de conduta.

A deliberação inteligente não tem a finalidade de impedir que o eu conheça as paixões provenientes dos desejos e dos impulsos; pelo contrário, sua função implica uma profunda busca por observar e conhecer os dados da experiência, os hábitos e impulsos do presente, para vislumbrar a probabilidade das tendências relativas ao comportamento e suas consequências para o meio social. Por isso, para o autor (idem, p. 179), a inteligência, que é deliberação, contém a significação do presente, objetivando assim uma síntese racional que viabiliza um "acordo entre os velhos hábitos e os novos impulsos".

O filósofo enfatiza que o fim de uma atividade e os princípios e ideais que a regem não significam o resgate de normas ou de objetivos pensados como bons e adequados para o futuro. Dewey (idem, p. 199) critica as filosofias utilitaristas que veem a deliberação como "cálculo estimativo dos cursos de ação", tendo por base "as perdas e os ganhos" futuros das diferentes vias de ação. Quando a ênfase é posta nos prazeres ou sofrimentos que poderão advir, desenvolvem-se decepções e frustrações pessoais, pois se acredita que o resultado de uma conduta será idêntico ao que foi imaginado. Ao considerar que o trabalho da inteligência e da deliberação é conhecer para desenvolver ações que solucionem as necessidades do presente, compreende-se que o benefício do resultado repousa na coordenação das atividades e não na exatidão do objeto previamente desejado.

\section{UMA NOVA DEFINIÇÃO DE NATUREZA HUMANA}

Nas três primeiras partes de Human nature and conduct, ao analisar o hábito, o instinto e a inteligência como componentes do psiquismo humano, John Dewey define o ser humano como predominantemente social. Na quarta parte do livro, o autor ratifica essa concepção por meio de uma tese cuja premissa menor diz que a natureza humana é em grande parte influenciada pela conduta moral; sua premissa maior considera que a conduta moral é social, e sua conclusão firma que a natureza humana é predominantemente social.

A premissa menor encontra-se no discurso em que Dewey (idem, p. 296), utilizando o recurso da analogia, afirma que "a natureza humana existe e opera em um ambiente", mas “não está 'dentro' do ambiente, tal como moedas estão em uma caixa, mas tal como uma planta está na luz e na terra". Assim, a natureza humana pertence 
ao ambiente social e é por ele influenciada, da mesma forma que uma planta perante as condições de luminosidade e as características do solo. Dewey (idem, p. 314) recorre a um exemplo para evidenciar que as relações sociais que influenciam e desenvolvem o humano são constituídas por condutas associadas: "quando uma criança age, aqueles que estão em seu entorno reagem. Eles a encorajam, aprovam ou reprovam”.

Considerando que as condutas associadas são essenciais no direcionamento da formação humana, implicando valorações dentre possibilidades alternativas, Dewey (idem, p. 278) reconhece que todas as formas de conduta incluídas nessas "possibilidades alternativas" - "questionamentos quanto ao melhor ou pior", "predicações" e "decisões acerca do melhor curso de ação" - são condutas morais. É assim porque, se as condutas têm consequências práticas, devido ao seu envolvimento com juízos, incentivos e reprovações, elas se localizam nos domínios da moral. Em decorrência disso, "dentre todas as temáticas, a conduta moral é a mais humana"; ela é "inextirpavelmente empírica" e "influencia diretamente a natureza humana", já que acarreta consequências práticas na formação de características e disposições (idem, p. 295).

Fica assim esclarecida a premissa menor do argumento, segundo a qual a natureza humana é predominantemente influenciada pela conduta moral; as disposições e os motivos das pessoas, bem como a significação de seus hábitos e impulsos, são formados e desenvolvidos em meio a condutas sociais e culturais, as quais, por envolverem valorações, juízos, escolhas, são de ordem moral.

O estabelecimento da premissa maior é feito por intermédio da afirmação de que a conduta moral é aprendida, direcionada e desenvolvida pela comunicação, sendo, então, eminentemente social. Dewey (idem, p. 314) faz uso de um exemplo, afirmando que o enunciado "Eles pensam" é "mais verdadeiro" do que "Eu penso", uma vez que as ideias não representam, inicialmente, ações voluntárias do indivíduo, pois o "conjunto de crenças e proposições" não é "originado" pela própria pessoa, chegando a ela "pelos outros, pela educação, pela tradição e sugestão do ambiente". Conhecemos aquilo que a vida associada "nos comunica"; conhecemos "de acordo com os hábitos" que a associação forma em nós; nosso conjunto ativo de hábitos apropria-se do que é comunicado pelo meio social, transformando determinados elementos em uma "asserção" que é por nós "aceita e posta em circulação".

Grande parte da comunicação responsável pela formação da pessoa ocorre, segundo Dewey (idem, p. 315), em função do intercâmbio de comportamentos: nós agimos e os outros reagem às nossas ações; nós passamos a prever as reações dos outros e pensamos em nossos próximos cursos de ação. Dewey nos leva a imaginar a formação de uma assembleia que se reúne para discutir e avaliar ações propostas e já realizadas; nesse cenário, a comunidade torna-se "um foro e um tribunal" que inicia um julgamento popular envolvendo acusações, valorações, atribuição de responsabilidades e justificativas. Com essa ilustração, o filósofo pretende mostrar que "nossos pensamentos e ações são preenchidos pelas ideias elaboradas pelos outros", as quais não são expressas unicamente por meio de instrução explícita, mas principalmente pela reação às nossas ações, ou seja, pela conduta moral compartilhada. É por isso que "nós aprendemos com" as outras pessoas, e é assim que se pode dizer que "existe consciência". 
Dewey (idem, p. 316) também mostra que a comunicação, cujos intercâmbios realizam "juízos morais", produz em nós a "responsabilidade moral", o que prova que toda conduta moral é social. Quando os outros nos comunicam seus juízos sobre as consequências de nossas ações, influenciam a formação de nossos hábitos, instintos, propósitos e ações futuros. Cientes desses juízos, nós nos tornamos responsáveis pelo que fazemos, passando a pensar sobre o que iremos fazer. Gradualmente, "por meio da imitação dramática", aprendemos a responder por nossas condutas, mediante o "reconhecimento deliberado de que as ações são nossas, de que as suas consequências vêm de nós mesmos".

Dewey (idem, p. 317) exemplifica dizendo que tanto uma atividade de interesse próprio quanto uma ação benevolente são "condicionadas pelas oportunidades sociais". A diferença repousa na qualidade e na intensidade das relações e interdependências. Por isso, não há por que "pensar a ação má como algo individual e a ação correta como algo social", pois todas "as ações de um indivíduo carregam a marca distintiva de sua comunidade", e a "dificuldade em ler essa marca deve-se à variedade de impressões decorrente da filiação a vários grupos". Os cursos de ação, bem como a aprovação ou reprovação a que as pessoas estão sujeitas, "são fatos da sociedade", são "fenômenos sociais".

Considerando que a definição "social" aplicada ao termo "conduta moral" é decisiva para validar a conclusão de seu raciocínio, o filósofo debate com teorias que conceituam a natureza humana como regida predominantemente por componentes inatos, devendo, por isso, ser direcionada por uma moralidade externa. Dewey argumenta que esse modo de compreender o humano é falacioso, pois exprime uma dicotomia entre o social e o natural, valorizando sempre um desses termos em detrimento do outro, o que significa separar, de um lado, uma suposta natureza humana e, de outro, os fatos sociais e concretos da vida associada.

Remetendo-se à filosofia grega clássica, particularmente a Platão, Dewey (idem, p. 50) rejeita o inatismo, a crença em uma razão transcendental em que as verdades morais são "supremas"; e também contraria o posicionamento de Aristóteles, que não leva em conta as circunstâncias sociais ao dizer que o universo deve ser julgado a partir do desejo e da disposição do homem bom. Para Dewey (idem, p. 33), "a influência dos costumes sociais, bem como dos hábitos pessoais, teria que ser levada em conta na apreciação de quem são o homem bom e o bom juiz".

Embora reconheça o valor do empirismo em Kant, Dewey (idem, p. 245) discorda da existência de princípios a priori que traduzem a dicotomia entre o natural e o adquirido; também vai de encontro à doutrina de que a "essência da razão é completamente universal”, a qual levou Kant a conceber a separação entre moral e experiência. Em outro extremo, Dewey contraria a tese das filosofias materialistas, segundo as quais nada pode ser feito antes que as instituições sociais mudem, como se a natureza do homem fosse completamente sujeita às forças do ambiente.

Dewey (idem, p. 297) também debate com o evolucionismo de Spencer, para quem existe uma natureza humana dotada de instintos hereditários, cujo progresso é representado pela proximidade com supostas leis ideais. Os que não se ajustam a esse desenvolvimento, como "o fraco e o ignorante", sofrem "os efeitos da violação 
da lei natural", enquanto os naturalmente aptos a se adequar, como "o sábio e o habilidoso", colhem as "recompensas de sua superioridade". Para Dewey (idem, p. 298), o problema dessa concepção é não perceber que, quando os homens passam a refletir sobre as condições sociais, essas próprias condições se alteram.

Dewey remete-se, então, ao evolucionismo de Darwin, argumentando que, por meio dessa visão, pode-se compreender que as modificações no ambiente servem a propósitos concretos. Para Dewey (idem, p. 284), "evolução significa continuidade de mudança", e essa mudança "deve assumir a forma de crescimento do presente em termos de complexidade e interação". Segundo a concepção deweyana, o evolucionismo darwiniano nos leva ao conhecimento dos fatos presentes na vida social e das ações que podem redirecionar a experiência e a formação humanas.

Mediante o estabelecimento das premissas "a natureza humana é predominantemente influenciada pela conduta moral" e "a conduta moral é social", o discurso deweyano pode ser concluído com o enunciado "a natureza humana é predominantemente social”. Influenciada pela conduta moral, que é acima de tudo social, a natureza humana é, para Dewey, igualmente social, diferindo das teses que a concebem como previamente formada.

\section{A PROPOSIÇÃO DE UMA NOVA CIÊNCIA PSICOLÓGICA}

Na quarta parte de Human nature and conduct, Dewey também expõe sua tese sobre a necessidade de uma ciência psicológica do social, uma ciência probabilística, competente para indicar as tendências de determinado conjunto de hábitos no decorrer do tempo. Segundo o que se encontra exposto no livro até então, tal ciência deverá ver os hábitos como gerados na coletividade, como de responsabilidade associada, resultantes da interação com os obstáculos que impedem a sua continuidade e permitem a liberação de impulsos, integrando assim um processo que envolve deliberação inteligente e formação de juízos práticos que visam obter a equilibração do eu e a previsão de condutas futuras.

No âmbito da comunidade, tal ciência terá por objetivo dar significação às condições sociais e culturais presentes formadoras do homem, e refletir sobre ações morais capazes de produzir mudanças no ambiente que contribuam para o desenvolvimento das pessoas. No que tange ao indivíduo, a ciência proposta tem a finalidade de ajudar na compreensão dos possíveis sentidos e tendências de hábitos e instintos, a fim de facilitar a escolha, dentre vários cursos de ação, de condutas morais que fortaleçam e emancipem os vínculos sociais.

O discurso de Dewey tem como premissa menor o enunciado "os fenômenos sociais podem ser estudados pela ciência”, e, como premissa maior, "a ciência ainda não é capaz de estudar os fenômenos sociais”. Esse raciocínio possui um diferencial - que será analisado logo mais - porque a sua conclusão é propositiva: "é preciso haver uma ciência para estudar os fenômenos sociais".

$\mathrm{O}$ estabelecimento da premissa menor é feito por intermédio de um recurso argumentativo, o modelo, com o intuito de propor que as ciências físicas estimulem 
ações no campo das humanidades. Segundo Dewey (idem, p. 324), a indústria moderna e o comércio são administrados com base no "controle das energias físicas decorrente de métodos próprios da investigação e da análise física”. Se observarmos o desenvolvimento dessas ciências físicas, mais precisamente da química, da biologia, da fisiologia e da medicina, encontraremos as "bases para o desenvolvimento de uma ciência do homem".

Dewey (idem, p. 84) considera que a nova ciência deva ser uma psicologia dos hábitos, cujo ponto de partida considere que o humano é formado socialmente. Tal psicologia "objetiva e social" possibilitará o tratamento científico dos fenômenos que envolvem a vida humana; seu cerne consistirá em olhar detidamente o conjunto de consequências das ações humanas e entender, probabilisticamente, "quais forças estão operando" (idem, p. 19). Nota-se que, para o filósofo, o caráter objetivo de tal ciência tem um qualificativo específico: a objetividade denota probabilidade, o que significa admitir a incerteza como elemento fundamental.

Segundo Dewey (idem, p. 49), as disposições, os fatos e os fenômenos estudados combinam certa regularidade de hábitos e costumes com o fato de que a atividade habitual "é sujeita a contingências, a circunstâncias que são imprevisíveis", podendo levar a ações cujo efeito é diferente do usual. Uma "teoria honestamente despretensiosa irá pautar-se na probabilidade da tendência, dispensando a matemática na moral"; entenderá "que as tendências fornecem a única instrução que podemos obter sobre o significado dos hábitos e das disposições", assumindo que um juízo moral nunca leva à certeza (idem, p. 51).

Dewey é enfático ao dizer que a psicologia, como ciência objetiva e social, não pode se contentar com o conhecimento das disposições da experiência presente, devendo estender-se também ao âmbito do juízo e da conduta moral mediante o exame de fatores que precisam ser modificados no momento e influenciam resultados posteriores. Na perspectiva da prática, essa psicologia social dos hábitos ajudará a entender "como direcionar nossas ações a fim de melhorar as condições" de sua efetuação.

Estabelecida a premissa menor de seu argumento, o autor passa ao raciocínio que firma a maior, cuja base consiste em mostrar que ainda não existe tal ciênciapor ele denominada "arte social" - capaz de fazer o estudo dos fenômenos sociais. Dewey (idem, p. 323) considera que, embora se possa argumentar que a referida ciência já se encontra formalizada, "a ciência humana tradicional não fornece esclarecimento" sobre as disposições psíquicas e as condutas morais, uma vez que ainda se fundamenta na existência de algo natural no homem, como também na crença de que a realidade presente deve se submeter a fins ideais futuros. Segundo a concepção deweyana, só uma ciência que adote uma nova visão sobre a natureza humana, que defina o humano como social, poderá proceder a tal estudo.

Dewey (idem, ibidem) diz que os sinais da exequibilidade da nova ciência estão presentes nos movimentos da psicologia clínica que, contestando a ortodoxia baseada em sensações conscientes, imagens e ideias, tentam entender e lidar com a natureza humana de maneira concreta. Acontece que o alcance desses movimentos ainda é bastante limitado, pois diferentes concepções teóricas ainda postulam "uma natureza humana artificial" que "não é passível de ser entendida e efetivamente 
direcionada com base em um entendimento analítico". Busca-se compreender as forças "que realmente movem a natureza humana" como abstrações da percepção e da observação, tomando-se uns "poucos fenômenos superficiais" para entender o conjunto de motivos, forças e ações (idem, p. 322).

Uma vez firmada a inexistência da ciência que almeja, Dewey chega à conclusão de seu raciocínio, a qual, conforme foi destacado acima, é propositiva, tendo a intenção de chamar a atenção para algo que ainda está por existir: é urgente constituir uma ciência capacitada a estudar os fenômenos sociais por meio da observação e análise do presente. Dewey defende a premência de tal ciência, propondo o debate e a mobilização para o desenvolvimento de suas bases, as quais virão contribuir efetivamente para o conhecimento dos fenômenos associativos e culturais.

Ao elaborar esse raciocínio, cuja conclusão é propositiva, Dewey pode ser integrado ao que se denomina "filosofia prática", caracterizada pelo uso de "silogismos práticos", os quais, na teorização de Aristóteles, contêm premissas que exprimem "um fim a ser alcançado e um meio pelo qual se pode atingi-lo, sendo o seu resultado uma ação" (Cunha, 2005, p. 18). Para Aristóteles, é no terreno da ação, ou da prática, que se consegue transformar o estado de coisas existente. Isto não significa que a filosofia prática renuncie à verdade, deixando de ser "ciência", mas a verdade não é o seu fim, constituindo "apenas um meio em vista de outro", sendo a ação "sempre situada no tempo presente" (Berti, 2002, p. 116).

Em Human nature and conduct, Dewey dialoga com as concepções que diferem da sua, buscando indicar caminhos para pensar o desenvolvimento da ciência proposta, mas não delineia formalmente os seus traços, não dita com precisão os seus termos. Dewey (2002, p. 86) limita-se a dizer que tal ciência psicológica será fundamental para o real entendimento dos hábitos, uma vez que "uma psicologia baseada nos hábitos (e nos instintos que se tornam elementos dos hábitos assim que agimos sobre eles)" voltará sua atenção para "as condições objetivas em que os hábitos são formados e operam", tornando-se, assim, uma psicologia que concebe o humano como social.

\section{AUDITÓRIO E ESTRATÉGIAS ARGUMENTATIVAS}

Seguindo os parâmetros da análise retórica mencionados na "Introdução" deste trabalho, pode-se dizer que o discurso de Dewey no livro Human nature and conduct é desenvolvido perante um auditório que sustenta convicções contrárias às suas. Esse auditório é composto por seguidores de diversas correntes de pensamento, como a filosofia grega clássica, em especial a decorrente de Platão e Aristóteles; as filosofias de Kant e Spencer; as elaborações utilitaristas e as psicologias elementistas e associacionistas, bem como as subjetivistas.

Reconhecendo as variadas disposições de sua audiência, Dewey debate as ideias centrais de seus interlocutores com o objetivo de articular novos consensos sobre os temas em pauta. Embora utilize várias estratégias argumentativas - como o exemplo, a ilustração e a analogia - para firmar suas teses perante esse auditório, 
o principal recurso discursivo de Dewey consiste em examinar as concepções de seus interlocutores por meio da dissociação de noções, técnica argumentativa que exprime uma "visão do mundo", oferecendo critérios de interpretação e de estruturação do real (Perelman; Olbrechts-Tyteca, 2002, p. 477).

Noções dissociadas resultam em pares filosóficos, nos quais um dos termos (nomeado Termo II) assume prioridade sobre o outro (nomeado Termo I), passando este a representar o que é considerado ilusório, errôneo ou aparente, aquilo que não se conforma à "regra fornecida pelo real” (idem, p. 473). O par filosófico que articula todo o discurso de Dewey em Human nature and conduct é o seguinte: ${ }^{2}$

\section{Natural (Termo I)}

Social (Termo II)

No decorrer do livro, é possível localizar uma série de outras noções vinculadas a essas, dependendo do tema específico em debate. Assim, por exemplo, ao termo "natural" associam-se "instinto" ou "impulso", "inato", "fixo" e "imutável", enquanto "hábito", "adquirido", "educável", "maleável" e "ativo" filiam-se a "social". De um lado, os defensores de doutrinas inatistas, para quem o homem possui caracteres pré-formados, sendo vítima de sua constituição predeterminada; de outro, os defensores da visão oposta, segundo a qual o homem é moldado exclusivamente por fatores adquiridos, não passando de uma presa do ambiente e das instituições.

À primeira vista, o discurso deweyano posiciona-se favoravelmente a "social" e contrariamente a "natural", conforme as definições usuais desses termos. No entanto, um exame mais detido revela que o que Dewey realmente busca contrariar são os posicionamentos parciais de seu auditório, os quais se situam tanto em um quanto em outro desses polos extremados. Segundo Pappas (2008, p. 175), a visão deweyana é uma composição de opostos que podem ser distinguidos sem apelar à cisão dualística, do que resulta um "equilíbrio integrativo" entre termos comumente situados em oposição. A razão disso é que, para Dewey, as oposições estão presentes na vida "de forma entrelaçada", devendo, por isso mesmo, coexistir.

As noções que melhor explicitam esse raciocínio são "arte"e "inteligência", segundo o que foi exposto nesse trabalho. Dewey lança mão da expressão "arte" para qualificar os hábitos, no intuito de exprimir a confluência entre repetição, treino, mecanismo e reprodução, de um lado, e reflexão, atividade, intelecto e renovação, de outro. A noção de "inteligência" traduz justamente a equilibração entre esses polos dispostos de maneira dualística pelo auditório, pois significa a equilibração entre "natural" e "social", termos que se conjugam na deliberação, ou seja, nas decisões que o homem toma para orientar sua conduta, tendo em vista o futuro. É na prática - termo fundamental no discurso

2 A disposição gráfica aqui adotada segue a indicação de Perelman e Olbrechts-Tyteca (2002). 
deweyano, conforme já foi aqui mencionado - que a deliberação inteligente assume a função de síntese racional entre as antinomias focalizadas por Dewey.

Para Dewey, o homem é, sim, social, mas isso não exclui a influência de componentes inatos; o homem não resulta exclusivamente de forças biológicas, como não constitui simples expressão de forças associativas cegas; sua essência não está em nenhum desses campos, isoladamente, e está em ambos, conjuntamente. Dewey deve essas noções a dois teóricos, William James (1842-1910) e George H. Mead (1863-1931), os quais, juntamente com ele e Charles S. Peirce (1839-1914), são considerados os fundadores do pragmatismo. As teses psicológicas de James e Mead representaram um rompimento com a tradição atomista da psicologia, que consistia em tratar o pensamento como aglomerado de ideias e sensações, de maneira compartimentada e estanque. ${ }^{3}$ Em vez disso, propuseram conceber a mente como instância de mediação entre o organismo e o meio social, a ser descrita pela noção de "continuidade", expressão de estados transitórios, processos.

A noção de "organismo", no âmbito do pragmatismo, advém dos avanços da biologia, como o próprio Dewey (1920/1959, p. 13) esclarece no livro Reconstrução em filosofia. Tais avanços viabilizaram uma nova visão do conceito de "experiência", bem como da relação entre razão e experiência; termos como "mente", "comportamento" e "atividade" passaram a ser vistos não como resultantes de aquiescência às intempéries do meio, mas da adaptação contínua do ser vivo - o homem, em particular - ao ambiente. Ao cérebro, como parte de um todo orgânico vivo e atuante, cabe a função de intermediar a relação de cada ser com os condicionantes ambientais que o cercam, para manter e ampliar as possibilidades de vida. O surgimento dessa nova concepção é atribuído por Dewey (1909/1997) a Charles Darwin (1809-1882), que abalou a teoria do conhecimento que dominava o campo filosófico desde a Grécia Clássica. Com o darwinismo, caiu por terra a crença tradicional de que os desígnios humanos são guiados por algo fixo e final que só pode ser apreendido por meio de uma inteligência contemplativa. A ideia de organismos que se adaptam e, assim, viabilizam a continuidade da vida tornou obsoleta a noção de uma força causal prévia, originada na esfera sobrenatural, responsável pela transformação do mundo e do próprio homem.

Em Human nature and conduct, Dewey segue os passos de James e Mead, aprofundando a divergência com a tradição filosófica, ao defender que a mente é uma instância biológica que se forma e se efetiva no âmbito social; a consciência é desenvolvida no processo de interação entre os organismos, em condições ambientais dadas. É por intermédio da noção de "organismo" que Dewey concebe o homem como um ser determinado por eventos naturais e que, ao mesmo tempo, age sobre esses mesmos eventos e a eles reage. A tese de que o organismo nunca é passivo origina a noção deweyana de "experiência", que reflete justamente uma adaptação singular que permite a utilização mais efetiva do meio em benefício do sujeito.

3 Dewey conheceu o livro Princípios de Psicologia de James, publicado em 1890, na Universidade de Michigan, onde trabalhou de 1884 a 1894, ao lado de Mead (Cunha, 1994). 
Do ponto de vista da análise retórica, pode-se concluir que Dewey trabalha com as noções dissociadas de "natural" e "social" porque assim raciocina seu auditório, que é responsável pela difusão de uma imagem fragmentada do mundo, típica da filosofia tradicional. O discurso deweyano, no entanto, visa promover o reencontro dessas mesmas noções em benefício de uma visão integrada do homem e do mundo, o que se faz por meio da noção de "organismo". É com base nessa visão que Dewey sugere a necessidade de uma ciência psicológica que tome por princípio o homem empírico, uma psicologia social que abarque os âmbitos do juízo moral e da conduta, voltada à compreensão e à transformação da cultura. Tal ciência terá como objeto de estudo os hábitos, que são a "chave para a psicologia social", conforme menciona o autor no prefácio do livro. Possibilitando a organização inteligente dos componentes psíquicos, tal ciência poderá contribuir para a formação mais adequada do ser humano, mantendo a esperança em um modo de vida democrático, segundo Dewey.

\section{CONSIDERAÇÕES FINAIS}

Embora o livro Human nature and conduct não seja dedicado a temáticas educacionais, as teses nele defendidas mantêm estreita relação com a educação. A principal contribuição da obra encontra-se na esfera da psicologia, propondo um novo status para a investigação psicológica no conjunto das ciências. Ao definir o ser humano como ser dotado de um aparato biológico maleável, que pode ser modificado e redirecionado em meio à experiência associativa, Dewey torna a psicologia comprometida não só com o estudo de dados individuais e coletivos, mas principalmente com a tarefa de situar esses mesmos dados no contexto da cultura, mediante o uso da inteligência para a adequada formação do comportamento moral.

Com suas reflexões, Dewey abre caminho para uma nova abordagem das filosofias que sustentam as diversas correntes psicológicas e educacionais de sua época e, mesmo, da atualidade. A noção deweyana de "objetividade", redefinida como "probabilidade", altera substancialmente a maneira de ver a ciência que investiga o psiquismo, modificando a visão predominante nas "ciências do homem", bem como na educação, usualmente marcada pelo enquadramento das certezas cartesianas. Tal redefinição encontra-se formulada em The quest for certainty, livro em que Dewey (1929) discorre sobre a história da ciência, buscando apoio na mecânica quântica para endossar um modelo diferenciado de procedimento científico e, consequentemente, propor uma inovadora teoria do conhecimento.

A chave da proposição deweyana é a renúncia à separação entre conhecer e fazer, caracterizando a ciência como união entre teoria e prática, como "resultado de operações experimentais dirigidas" em que se conjugam dados sensíveis e racionais (idem, p. 171, tradução nossa). Sua argumentação visa retirar a noção de verdade do âmbito da certeza para situá-la na esfera da probabilidade, lançando mão, para isso, dos conceitos introduzidos nos anos de 1920 por físicos como Niels Bohr (1885-1962) e Werner Heisenberg (1901-1976), que questionaram o determinismo da física newtoniana (Costa-Lopes, 2010). 
O sustentáculo dessa visão é sintetizado pelo "princípio da incerteza" de Heisenberg (1999, p. 75), para quem um evento atômico "é uma função de probabilidade, uma expressão matemática que traz consigo tanto enunciados sobre possibilidades ou tendências, como afirmações sobre nosso conhecimento de fatos". Assim, não é possível "objetivar completamente o resultado de uma observação experimental", como também não é possível "descrever o que 'acontece' entre essa observação e a seguinte"; o ato de investigar combina "elementos objetivos e subjetivos", uma vez que comporta asserções que não dependem do observador e que podem "diferir de um experimentador a outro" (idem, p. 78-79).

Ao redefinir a psicologia como ciência social envolvida com problemas da esfera da moral e da cultura, Dewey a situa como ciência fundamental da educação, uma vez que os conhecimentos por ela gerados passarão a oferecer contribuições decisivas para a formação do homem. A psicologia dedicada ao estudo dos hábitos facilitará a compreensão das influências que operam no processo educativo, permitindo enxergar o que precisa ser modificado. A aliança entre psicologia e educação possibilitará a formação de um eu moral capaz de deliberar inteligentemente sobre os fatos da vida privada e coletiva.

Tais propostas, no entanto, devem ser discutidas perante as suas implicações, tanto na filosofia quanto na psicologia e na educação. As teses deweyanas podem ser enquadradas no rol das filosofias "falibilistas", cuja visão do real baseia-se na "insuficiência" de nosso conhecimento (Dutra, 2005, p. 77); opõem-se, portanto, ao "fundacionismo", que defende o caráter inquestionável do saber humano como "ponto de partida inabalável na consideração das questões filosóficas, do conhecimento e da conduta humana" (idem, p. 13). O questionamento que se pode fazer a Dewey é se a sua concepção falibilista "permite a produção de conhecimentos válidos, seguros e confiáveis", ocasionando a intervenção em situações práticas - incluindo as situações escolares - sem dar margem ao "espontaneísmo" (Costa-Lopes, 2010, p. 101-102).

Costa-Lopes (idem, p. 103) sugere que a resposta a essa indagação pode ser buscada nos argumentos do próprio Dewey, para quem "a ciência contemporânea não perde a esperança de elaborar uma imagem real do mundo, mesmo sabendo que só é capaz de obtê-la em termos probabilísticos". A consciência dessa limitação já é comum nas ciências experimentais e também na filosofia, que opera "no campo da moral, dando preferência a 'asserções garantidas' em lugar de enunciados 'verdadeiros', e nem por isso abdicando de ter a verdade em seu horizonte".

A nova ciência será útil à educação? Permitirá pensar, de maneira mais precisa e adequada, a formação humana que se busca atingir nos diversos espaços educativos, incluindo a escola? Quais novas metodologias de ensino poderão ser geradas a partir dela? Estes são questionamentos justos e necessários, mas que não são passíveis de resposta pormenorizada antes que a aludida ciência se desenvolva, quando então será possível elaborar a sua transposição para a esfera das práticas pedagógicas. No âmbito das formulações de Dewey, em consonância com os demais pragmatistas, as questões práticas não se resolvem em teoria, mas somente por meio da aplicação de formulações teóricas a situações reais. 
Essa última formulação, no entanto, contém outra limitação a ser enfrentada pela teoria deweyana: se as dificuldades não se resolvem senão na prática, e se o que se observa na prática é que a vida associativa expressa a desigualdade de oportunidades entre grupos e classes sociais, tornando a experiência humana marcada pelo dualismo, como poderá prevalecer o pensamento inteligente reivindicado pelo autor?

Pode-se buscar uma resposta a essa indagação recorrendo novamente ao próprio Dewey. Como foi sugerido neste trabalho, o discurso deweyano possui características de uma "filosofia prática", cuja intenção não é apresentar soluções, mas incitar à busca de alternativas por meio de raciocínios que indicam carências, na expectativa de motivar ações que superem o atual estado de coisas. Segundo Cunha (2001), a noção deweyana de democracia é um bom exemplo disso, pois Dewey, embora apresente o modo de vida democrático como desejável, reconhece os entraves práticos que impedem a sua plena realização na sociedade contemporânea. Mas, mesmo assim, Dewey fomenta iniciativas nessa direção.

Cunha (2010) sugere que o objetivo do discurso deweyano é apresentar problemas a serem enfrentados por todos os que consigam identificá-los e queiram mobilizar-se para solucioná-los. O mesmo pode ser dito quanto à proposta de uma nova psicologia e de uma nova educação: nem uma nem outra estão prontas, e talvez jamais estejam; por isso, as suas proposições constituem desafios lançados por Dewey, para que a sua realização seja tentada. Tais desafios devem ser examinados no âmbito da moral, cabendo questioná-los no que tange à sua adequação aos desejos e possibilidades de cada um e da coletividade.

Essa talvez seja a maior limitação da teoria deweyana, na sociedade contemporânea, que se norteia cada vez mais por anseios de realização imediata, por resultados observáveis e seguros, por eficiência e produtividade, tanto nos afazeres cotidianos quanto nas práticas científicas e escolares. Até que ponto a difusão da filosofia de Dewey poderá contribuir para amenizar essa tendência?

\section{REFERÊNCIAS}

Berti,Enrico. Aristóteles no século XX.Tradução Dion Davi Macedo. São Paulo: Loyola,1997. . As razốes de Aristóteles. Tradução Dion Davi Macedo. São Paulo: Loyola, 2002.

Costa-Lopes, Viviane. O ceticismo em John Dewey: a busca da certeza. 2010. 122f. Tese (Doutorado em Educação Escolar) - Faculdade de Ciências e Letras, Universidade Estadual Paulista, Araraquara, 2010.

Cunha, Marcus Vinicius. John Derwey: uma filosofia para educadores em sala de aula. Petrópolis: Vozes, 1994.

. John Derwey: a utopia democrática. Rio de Janeiro: DP\&A, 2001.

. Comunicação e arte, ou a arte da comunicação, em John Dewey. Revista Brasileira de Estudos Pedagógicos, Brasília: INEP, v. 86, n. 213/214, p. 9-20, maio/dez. 2005.

.Experiência, poética e utopia na educação.In: PAGNI,Pedro Angelo; GeLAmo, Rodrigo Pelloso (Orgs.). Experiência, educação e conteimporaneidade. Marília: Poiesis, 2010. p. 229-235. 
Dewey,John. Psychology as philosophic method. Mind, Oxford,v.11,n. 42,p. 153-173,1886. . The need for social psychology. Psychological Revierw, Washington: APA, n. 24, p. 266-277, 1917.

. The quest for certainty: a study of the relation of knowledge and action. New York:

Minton, Balch \& Company, 1929.

.Democracia e educação: introdução à filosofia da educação. Tradução Godofredo Rangel e Anísio Teixeira. 3. ed. São Paulo: Nacional, 1958.

Nacional, 1959.

.The influence of darwinism on philosophy. In: . The influence of darwinism on philosophy and other essays. New York: Prometheus Book, 1997. p. 1-19.

The reflex arc concept in psychology. In: Hickman, Larry; Alexander, Thomas. The essential Derwey: ethics, logic, psychology. Indianapolis: Indiana University, 1998. v. 2, p. 3-10. Human nature and conduct. an introduction to social psychology. New York: Prometheus Books, 2002.

Teoria da valoração. In: . A valoração nas ciências humanas. Tradução Marcus Vinicius da Cunha, Ana Raquel L. Cianflone e Erika N. F. de Andrade. Campinas: Autores Associados, 2009. p. 51-120.

Dutra, Luiz Henrique de Araújo. Oposições filosóficas: a epistemologia e suas polêmicas. Florianópolis: UFSC, 2005.

Heisenberg, Werner. Física e filosofia. Tradução Jorge Leal Ferreira. 4. ed. Brasilia:UnB,1999. PAPPAs, Gregory Fernando.John Dewey's ethics: democracy as experience. Bloomington:Indiana University, 2008.

Perelman, Chaïm; Olbrechts-Tyteca, Lucie. Tratado da argumentacãao: a nova retórica. Tradução Maria Ermantina Galvão. 5. ed. São Paulo: Martins Fontes, 2002.

Toulmin, Stephen. Os usos do argumento. Tradução Reinaldo Guarany. São Paulo: Martins Fontes, 2001.

\section{SOBRE OS AUTORES}

Erika Natacha Fernandes de Andrade é doutoranda em educação pela Universidade Estadual Paulista (UNESP).

E-mail: erikaandra@hotmail.com

Marcus Vinicius da Cunha é doutor em história e filosofia da educação pela Universidade de São Paulo (USP). Professor associado da mesma instituição. E-mail:mvcunha2@hotmail.com

Recebido em outubro de 2010 Aprovado em novembro de 2011 


\section{ERIKA NATACHA FERNANDES DE ANDRADE E MARCUS VINICIUS DA CUNHA}

\section{O discurso psicológico de John Dewey}

Este trabalho examina o discurso do filósofo e educador americano John Dewey (1859-1952) sobre o tema "natureza humana", adotando como referência o livro Human nature and conduct: an introduction to Social Psychology. Nesse livro, publicado em 1922, Dewey discute conceitos fundamentais da psicologia - instinto, hábito, inteligência e outros - e propõe uma nova ciência psicológica; suas elaborações abrangem os campos da filosofia, da psicologia e da educação. A metodologia para análise do discurso segue os estudos desenvolvidos pelo Grupo de Pesquisa Retórica e Argumentação na Pedagogia, os quais se baseiam nas teorias de Chaïm Perelman e Stephen Toulmin.

Palavras-chave: John Dewey; psicologia social; fundamentos da educação; análise retórica.

\section{John Dewey's psychological discourse}

This work examines the discourse of the American philosopher and educator John Dewey (1859-1852) about "buman nature", adopting as reference the book Human nature and conduct: an introduction to Social Psychology. In this book, published in 1922, Derwey discusses fundamental concepts of Psychology - instinct, habit, intelligence, and others - and proposes a new psychological science; the author's elaborations cover the fields of philosophy, psychology and education. The methodology to analyze his discourse follows the studies developed 
by the Research Group "Rhetoric and Argumentation in Pedagogy". Such studies are based on Chaïm Perelman's and Stephen Toulmin's theories.

Keywords:John Dewey; Social Psychology; educational foundations; rhetoric analysis.

\section{El discurso psicológico de John Dewey}

Este artículo analiza el discurso del filósofo y educador norteamericano John Dewey (1859-1952) sobre el tema "naturaleza humana", y adopta como referencia el libro Human nature and conduct: an introduction to Social Psychology. En ese libro, publicado en 1922, Derwey discute los conceptos fundamentales de la psicología - el instinto, el hábito, la inteligencia y otros - y propone una nueva ciencia psicológica; sus elaboraciones cubren los campos de la filosofía, la psicología y la educación. La metodología para el análisis del discurso sigue los estudios desarrollados por el Grupo de Investigación "Retórica y argumentación en la Pedagogia" que se basan en las teorias de Chaim Perelman y Stephen Toulmin.

Palabras clave:John Derwey; Psicología Social; fundamentos de la Educación; análisis retórica. 